\title{
Testing An EngIneERING DeSIgn TeACHING TeCHNIQUe FOR IMPROVING SELF-EFFICACY AND BELONGING in Physics 11 Classrooms
}

\author{
Katherina V. Tarnai-Lokhorst \\ Camosun College \\ lokhorst@camosun.ca
}

\begin{abstract}
Girls participate equally with boys in Physics 11 classrooms in the Greater Victoria Region in British Columbia but exhibit lower levels of self-efficacy in physics, lower beliefs in control over their own destiny and lower perceptions of the value of physics as a career.

The hypothesis tests a new paradigm for teaching high school physics that is demonstrably simple to implement, eases teacher workload and creates an effective tool to enhance student learning. Developed using participatory action research with Physics 11 teachers, an unconventional lesson plan guides facilitators of learning through a discovery-based teaching paradigm that constructs knowledge using the engineering design process.

Survey data reveals the activity may significantly dispel gendered perceptions by eliminating differences in beliefs of boys and girls in Physics 11 and increase students' level of comfort in the classroom, factors predicted to influence self-efficacy.
\end{abstract}

Keywords: gender, career, physics 11, gendered careers, destiny, control

\section{INTRODUCTION}

Many studies explore the performance differences between girls and boys in introductory physics classes [1], [2]. This study explores student perceptions and beliefs as factors that may relate to performance through selfefficacy [3], [4]. Girls and boys participate equally in Physics 11 classrooms in the Greater Victoria Region in British Columbia but typically exhibit lower levels of self-efficacy in physics, lower beliefs in control over their own destiny and lower perceptions of the value of physics as leading to a viable set of career options. Three primary factors for these differences in beliefs and perceptions include: stereotypical beliefs about engineering as a gendered career [5], perceptions that physics is a dead science with nothing new to discover, and inabilities to visualize how applications of physics can make the world a better place, factors linked to women's career aspirations [6], [7].

This research seeks to diagnose the perceptions and beliefs of male and female students in Physics 11 classrooms and tests a potential solution to mitigate precluded interests in gendered careers [8], [9]. The hypothesis is that instilling a new paradigm for teaching high school physics, by using a demonstrably simple student-centred implementation process that eases teacher workload, will create a useful and effective tool to enhance student learning and create a statistically significant improvement in girls' perceptions and beliefs about their self-efficacy in physics, an indicator of student success and motivation [2], [4], [10]. The method is applicable to most concepts within the Physics 11 curriculum and provides an alternative to additive activities (such as school outreach programs) by creating the opportunity for systemic change.

The mixed methods research program generated quantitative and qualitative data that appears to support the hypothesis that connecting physics to scenarios derived from the students' life experiences enhances girls understanding of the social benefits realized through engineering [11]. Participatory action research with Physics 11 teachers led to the development and implementation of an unconventional lesson plan that constructs knowledge through a discovery- or inquirybased teaching paradigm based on the engineering design process. Survey results quantify the impact of introducing these principles into the teachers' Physics 11 classrooms. Data acquired before and after the research activity identify trends indicating that this activity may significantly dispel gendered perceptions, eliminate differences between the beliefs of boys and girls in Physics 11 and increase students' level of comfort in the classroom.

\section{PARTICIPATORY ACTION RESEARCH}

Participatory action research, PAR, is a qualitative methodology that involves subjects directly in both planning and implementing the research project [12]. In this work, the Physics 11 teachers met to review literature documenting the low conversion rates of female students from Physics 11 to higher education in engineering or physics. Together with the principal researcher, the PAR Team identified potential strategies aimed at mitigating the apparent barriers to girls in their classrooms. In this way, the teachers acquired and created shared knowledge 
about dispelling stereotypes and beliefs of gendered careers, and created the lesson plan activity, which is central to this research.

Physics 11 is identified as a key course in the leaky pipeline or pathway to engineering [3], [5], [7], and [8] because girls in British Columbia participate at a high rate, near parity with boys, but do not generally persist in physics or engineering (while physics is an excellent subject for general knowledge of non-practitioners, the physical disciplines of engineering - civil, mechanical, electrical and mining, in particular- suffer from a dearth of women). Data from Camosun College, sorted by decade between 1975 and 2015, indicates that women consistently comprise roughly $40 \%$ of students who register at the post-secondary college with Physics 11 credit [15]. Less than 5\%, however, choose engineeringrelated programs (engineering transfer, engineering technology, computer science, web design, et cetera), whereas the majority of these women pursue programs in business, non-engineering scientific pursuits like health or natural sciences, or undeclared general studies. Interestingly, the percentage of female students with Physics 12 credit is substantially lower at less than $20 \%$. With most British Columbia post-secondary institutions requiring two of three high school sciences for admission (in addition to one high school language and normal graduation requirements; the science choices are physics, chemistry and biology) [16]-[18], girls appear to be regularly including Physics 11 as one of those sciences but most do not continue to Physics 12 .

\subsection{Sample Population of PAR Team Teachers}

The Capital Regional District has 13 public schools in three school districts and five independent private schools. Of the 26 Physics 11 teachers identified for this 2015 study, three were women; one elected to participate in the research.

The five teachers of the PAR team represented each group of schools: two teachers were from a school in School District (SD) 61, one teacher from SD62, one from SD63 and one from an independent school. The teachers had similar educational backgrounds and years of experience (Table 1). All completed undergraduate degrees with a science focus, most in Physics. Four of the teachers completed Bachelor degrees in science and four teachers completed Bachelor degrees in education. Three of the five teachers completed Masters degrees. The teachers each acquired between 17-35 years of teaching experience, with 12 years being the shortest time spent in the current school.

All teachers were born and raised in Canada. Three of the teachers grew up in the Victoria region, one in New Brunswick and one in Ontario.

\begin{tabular}{|l|l|l|l|l|}
\hline \multicolumn{5}{|l|}{ Table 1} \\
PAR Team teacher education and experience \\
\hline $\begin{array}{l}\text { School } \\
\text { Group }\end{array}$ & Education & $\begin{array}{l}\text { Desire to } \\
\text { obtain more } \\
\text { education? }\end{array}$ & $\begin{array}{l}\text { Experien } \\
\text { ce (yrs) }\end{array}$ & $\begin{array}{l}\text { Current } \\
\text { School } \\
\text { (yrs) }\end{array}$ \\
\hline SD 63 & B.Ed. Physics/Math & maybe & 25 & 23 \\
\hline SD 62 & B.Sc.; B.Ed.; M.Sc. & yes & 17 & 12 \\
\hline SD 61 & B.Sc., Physics & yes & 23 & 19 \\
\hline SD 61 & $\begin{array}{l}\text { B.Sc.; B.Ed. Secondary } \\
\text { Science; MA, Teacher } \\
\text { Leadership }\end{array}$ & yes & 20 & 16 \\
\hline $\begin{array}{l}\text { Indepen- } \\
\text { dent }\end{array}$ & $\begin{array}{l}\text { B.Sc., Environmental } \\
\text { Science; B.Ed., Science; } \\
\text { M.Ed, Curriculum } \\
\text { Studies }\end{array}$ & yes & 31 & 26 \\
\hline
\end{tabular}

Table 1: PAR Team teacher education and experience.

\subsection{Sample Population of Students}

The student sample was drawn from the PAR Team teachers' classes. All students in these classes were invited to participate and were asked to complete identical paper surveys before and after the in-class activity and once again online several months later. Due to student absences during the second survey deployment, the number of respondents to the paper surveys is unequal. The sample size of students who completed the survey prior to participating in the activity is 250 , with 21 responses missing data, leaving 229 valid responses. Of these students, $54 \%$ were female, $46 \%$ male. Post-activity, 224 students completed the survey with 6 surveys missing data leaving 218 valid responses, of which $52 \%$ were completed by female students, $48 \%$ by male students (Figure 1). Paper surveys achieved a response rate of $100 \%$. During the online deployment, however, only 71 surveys were completed with 23 missing data, leaving a total of 48 valid responses for sex. Of the online survey respondents, $62 \%$ were female.

The use of sex instead of gender in the survey is deliberate and intended to eliminate potential confusion surrounding gender identification [19], [20]. In spite of this, some students wrote comments on their surveys complaining about the binary option for sex responses. All non-disclosure of sex is necessarily eliminated as

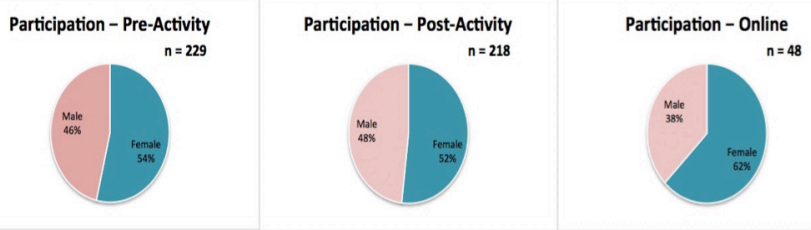

Figure 1: Student participation by sex. 
missing data. In the remainder of this paper, "gender" is again used in place of "sex" to align with common social practice.

The Physics 11 classrooms in this study exhibited gender parity. Although the independent school may skew the results (it is an all-girls' school), several of the mixedgender classes exhibited higher percentages of female students than male students. The high percentage of girls in Physics 11 posited from this and other studies [4], [6], may indicate that through the late $20^{\text {th }}$ century British Columbia schools significantly reduced barriers to girls' pursuit of mathematics and physics through the middle and high school years, repairing several early leaks in the pipeline, removing invisible barriers in the pathway and providing increased access to engineering.

\subsection{PAR Activity Design}

Redesigns of experiments that use dated apparatus, such as the "ticker-tape" experiment (Figure 2) used to test theoretical formulas for kinematics since pre-1940, could effectively dispel perceptions that physics is an old science with little new to learn. Similar to their predecessors, the research team teachers enjoy using the ticker-tape apparatus in their classrooms and directed the activity development towards exploring the concept of friction. The PAR Team teachers had extensive experience teaching Physics 11. Although they no longer use lesson plans to guide their delivery of experiments, they acknowledged that newer teachers to Physics 11 would benefit from detailed lesson planning documentation, especially with the proposed teaching paradigm based on the engineering design process.

The PAR Team spent much of the scheduled lesson planning time building their relationships with each other, something they said is missing in teacher development. Conversations would devolve into descriptions of funny episodes in their classrooms instead of articulating their teaching processes (Figure 3). Eventually, the team managed to create a lesson plan in two documents: a teacher guide and a student guide (available upon request). In order to provide consistent experiences for all students, the teachers requested that the principal investigator facilitate the activity in all classrooms. Later, the teachers admitted they were uncertain about how to implement the

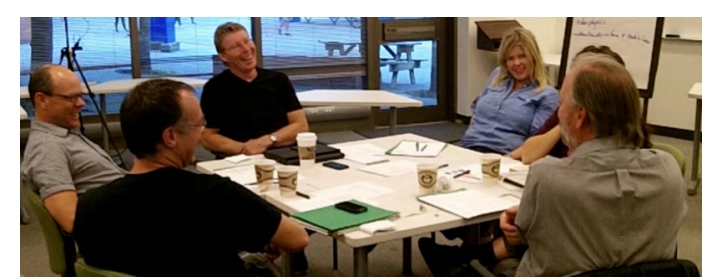

Figure 3: The PAR Team discussions on labs, apparatus and procedures often followed tangential paths into classroom anecdotes.

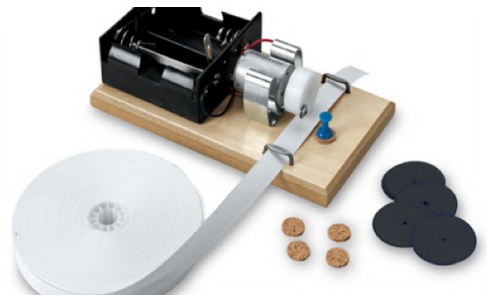

Figure 2: Ticker tape (ticker-timer) apparatus for studying velocity and acceleration in Physics 11 classrooms [23].

new teaching paradigm without first observing the technique. This indicates a need for future teacher training workshops.

The greatest change proposed and eventually implemented related to the activity process and how the teacher-facilitator presents the physics concept (see Figure 6 in the Appendix). In the typical physics teaching paradigm, the teacher introduces a concept theory prior to running experiments or discussing contextual applications. The experimental objective is to verify or demonstrate the theory. Teachers then encourage the students to extrapolate implementation contexts through discussions that follow the experiment. The focus of the student lab report is on theory, procedures, data collection and applying that data to the theoretical equations. Report conclusions recount how well the experiment matched the theory by expressing the observed experimental results in comparison to the expected theoretical result. This process is unquestionably necessary for reinforcing the scientific method of theoretical proofs that students need to learn.

In the research activity process, the teacherfacilitator begins with a pre-lab discussion, prompting students to share contextual examples from their personal experiences (Figure 4). Once a few ideas have been generated, students form small groups at lab tables where they discuss their scenarios and select one to explore. They draw the scenario on a half-sheet of flipchart paper and identify possible improvements to the scenario. Next, the students develop a verification experiment to test




whether the changes they propose will result in the improvements they predict. Using materials available in the lab or classroom, the small groups design, sketch and build prototypes of their scenario, including some sort of changeable design feature to represent the two configurations they will test and compare. They run their experiment to attempt validation of their hypothesis, quantifying input data with measurable units, generating output data and including all descriptors necessary to distinguish the two scenarios in their data records. Students analyse their data as they conduct their test for two reasons: to verify that their experiment indeed tests what the group intended to test, and to allow the students to make immediate changes to the experiment design, if necessary, recording each revision and its purpose. Using discussion questions as a guide, the students report back to the teacher on their scenario sketches, keeping their real-world context front and centre in their thoughts throughout the activity (Figure 5).

\section{RESEARCH RESULTS}

The preliminary quantitative analyses tested several hypotheses about the validity of destiny and control, selfefficacy in physics, alienation and independence, and belonging as predictors of educational pursuits in a fundamental manner. The analyses in this paper examine belonging, destiny and control for two cases: potential differences within the dataset split by gender of student responses collected before and after the implementation of the in-class activity, and potential differences between male and female student responses within each survey deployment.

The trends identified in the quantitative data analyses give some insight into the challenges facing the engineering community in their efforts to recruit and retain women in engineering. The youth survey (survey copies available upon request) probes the sample population's beliefs and perceptions about a broad variety of factors. This paper explores results from questions that

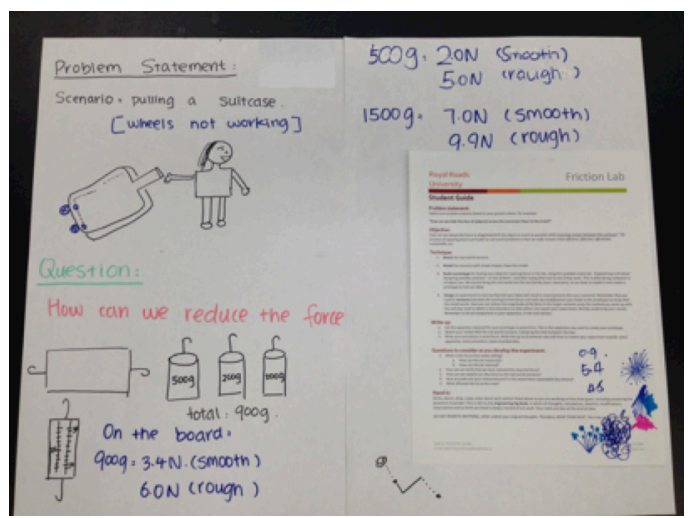

Figure 5: Suitcase example including Student Guide, which this group followed closely. probe beliefs about nebulous concept of control over one's future and perceptions about one's connectedness to their community. Exploring changes in the social motivations of young women in high school physics may help diagnose the low transition rates of women into engineering education and careers.

\subsection{Perceived Value of Physics}

In sorting their favourite courses, male students ranked mathematics and physics classes as their first and second choices. Female students ranked mathematics first but physics seventh, after language, social sciences, art, chemistry and biology. This order of favourite courses only minimally changed after the activity (female students switching the placement of biology and chemistry, and social sciences and art; male students switching the placement of language and trades, with language becoming more preferred).

Student perceptions about the value of physics did not significantly change after the activity. However, questions about the perceived value of art and social science did produce statistically significant results. In particular, belief that social science leads to a promising career trends upwards by $3 \%(\alpha=0.25)$ as did belief that art leads to a promising career. This may have been due to the drawing and sketching components of the activity and the increased focus in the physics classroom discussions on the relevance of social action.

\subsection{Destiny and Control}

Although the destiny and control questions do not overtly relate to physics, as the examples show below, they elicit responses within the context of physics. Female student responses to questions about the likelihood of getting their desired job significantly changed after the activity, increasing by almost $7 \%(\alpha=0.10)$, from their pre-survey responses. Male responses indicated similar likelihood beliefs but did not significantly change with the activity. That being said, differences between male and female responses became significant in the post-activity survey deployment, with female responses slightly more likely than male responses (female average of $x=2.17$, $\mathrm{SD}=0.74$, compared to male $\mathrm{x}=2.13, \mathrm{SD}=0.62$, on a Likert scale where 1="not likely or possibly", $2=$ "likely" and 3="very likely").

The activity appeared to create additional differences between male and female responses in two questions. For the question "I feel that the future holds nothing for me to fear", female students agreed with this statement at a significantly higher rate than male students, which may indicate an increased sense of confidence following the activity. This outcome was qualitatively supported by the teachers in our debriefing interviews (prior to the data 
analysis, so therefore independently sourced). For the question "I have often found that what is going to happen will happen no matter what", male and female responses were significantly different with male students agreeing to the statement more frequently than female students before and after the activity. This outcome may indicate a trend that girls experience an increased sense of control over their destiny with regards to the physics classroom.

Several questions relating to destiny and control returned statistically significant differences between female and male responses before the activity that were eliminated following the activity:

- "There will always be wars, no matter how hard people try to prevent them."

- Pre-activity survey resulted in two degrees of freedom, $\mathrm{df}=4$, and a Pearson Chi-Square value of $\mathrm{X} 2=24.497$, well above the required values for four degrees of freedom of $14.86(\alpha=0.005)$, rejecting the null hypothesis that no change exists.

- "The world is run by the few people in power, and there is not much the little person can do about it."

- Pre-activity survey resulted in two degrees of freedom, $\mathrm{df}=4$, and a Pearson Chi-Square value of $\mathrm{X} 2=10.760$, above the required values for four degrees of freedom of $9.490(\alpha=0.05)$, rejecting the null hypothesis that no change exists.

These outcomes may indicate a trend that as girls' selfefficacy increases their sense of fatalism decreases.

In all other questions related to destiny and control, male and female responses were not statistically different before or after the activity and did not statistically change. For the questions discussed, statistically significant differences in male and female responses prior to the activity disappeared following the activity. This seems to indicate a trend toward dispelling of any gendered beliefs following the activity.

\subsection{Comfort with Physics}

The quantitative data did not provide statistically significant results regarding comfort with physics. However, the qualitative results collected through teacher interviews following the activity identify increases in the involvement of both students and teachers in the new teaching paradigm. The teachers stated their interest in using the PAR development process and keenly observed and emulated the facilitation techniques used in class. During the documentation phase, for example, the teachers tended to join in with the students in solving their design challenges. In some cases, the principal investigator needed to quickly follow up with mitigating statements to the students, such as "... if you would like to" or "... if that makes sense to you". Once the students were again on their way, teachers were reminded of their role as coach or facilitator. The students were to come up with their own ideas for design changes and prototypes.

When a teacher intervened and suggested methods, the students visibly withdrew from the activity by sitting back from their work space and becoming less active in demeanour, where prior to the intervention they were laughing and working with enthusiasm. In one case, for example, a group of female students held an energetic discussion about their prototype design. They scanned the classroom in search of materials they could use when the teacher walked up and told them to use the blocks and spring scales set up on a side table ahead of the class time. Only after the teacher moved on did student enthusiasm return to its previous level.

Overall, male and female student participation rates increased over previous lab activities, perhaps because the requirement of drawing their scenario drew in students with an affinity for art, while the exploratory prototyping using materials around the classroom may have appealed to students with a preference for kinaesthetic learning [21]. In any event, the small groups enabled all students to participate in the learning activity, providing each individual the space to explore and create knowledge in ways that are personally meaningful [22].

The most observable results pertained to the increased participation of students in the in-class activity. Student scenarios came from workplaces, sporting activities and home life. Examples included shifting boxes filled with inventory, increasing the resistive load of a rugby scrum machine, or trying to move a piano or a bouncy castle. The broad range of topics may have led to the increased perception of the social relevance physics. In the majority of student reports, the drawings were detailed and colourful, perhaps leading to the increased perceptions of the relevance or career possibilities related to art.

\section{CONCLUSIONS}

The relationship between societal beliefs and gendered career choices is becoming clearer. Data from the Greater Victoria school system presented in this paper indicate interesting impacts on the beliefs and perceptions of male and female students apparently due to a new inclass activity based on the engineering design process.

The in-class activity resulted in qualitatively assessed higher engagement of both male and female students in the physics activities provided the teacherfacilitators permitted students to create knowledge with 
their peers. The quantitative analyses indicate trends in higher perceived value in art and social sciences, higher perceived self-efficacy in physics, increased control over their own destiny, and the dispelling of gendered beliefs and perceptions. Whether the changes persist and influence student post-secondary educational decisions can only be determined through future deployments of the survey instrument and longitudinal studies focused on students' ultimate career choices.

\section{Acknowledgements}

I wish to acknowledge the funding support from the Camosun College Faculty Association, Engineers Canada, and TD Insurance Meloche Monnex. Without your financial support, I could not have pursued this research program, which continues.

\section{References}

[1] L. E. Kost, S. J. Pollock, and N. D. Finkelstein, "Investigating the source of the gender gap in introductory physics," AIP Conf. Proc., vol. 951, pp. 136-139, 2007.

[2] J. Docktor and K. Heller, "Gender Differences in Both Force Concept Inventory and Introductory Physics Performance," AIP Conf. Proc., vol. 1064, no. March 1995, pp. 15-18, 2008.

[3] M. Alvesson and Sköldberg, "(Post -) positivism , social constructionism, critical realism : three reference points in the philosophy of science," in Reflexive Methodology: New vistas for qualitative research (2nd Ed.), vol. 15, London: Sage, 2009, pp. 15-52.

[4] V. Sawtelle, E. Brewe, and L. H. Kramer, "Exploring the relationship between self-efficacy and retention in introductory physics," J. Res. Sci. Teach., vol. 49, no. 9, pp. 1096-1121, 2012.

[5] K. V. Tarnai-Lokhorst, "Where are the women? Perceived Barriers to Engineering Education: A review of feminist influences on curriculum in British Columbia that contribute to the persisting and evolving barriers to women's entry into engineering education," in ASEE-SE Conference, 2015.

[6] L. E. Kost, S. J. Pollock, and N. D. Finkelstein, "Unpacking gender differences in students' perceived experiences in introductory physics," AIP Conf. Proc., vol. 1179, pp. 177-180, 2009.

[7] M. Levin, Y. Xie, K. A. Shauman, K. N. Ray, and F. McDonnell, "Why so few choose physics: An alternative explanation for the leaky pipeline," Am. J. Phys., vol. 73, no. 7, pp. 583-586, 2005.

[8] S. Cheryan and V. C. Plaut, "Explaining Underrepresentation: A theory of precluded interest," Sex Roles, vol. 63, no. 7-8, pp. 475-488, 2010.

[9] J. A. Forsman and J. M. Barth, "The Effect of Occupational Gender Stereotypes on Men's Interest in Female-Dominated Occupations," Sex Roles, no. Fine 1996, pp. 1-13, 2016.

[10] H. M. G. Watt, J. D. Shapka, Z. A. Morris, A. M. Durik, D. P. Keating, and J. S. Eccles, "Gendered motivational processes affecting high school mathematics participation, educational aspirations, and career plans: a comparison of samples from Australia, Canada, and the United States.," Dev. Psychol., vol. 48, no. 6, pp. 1594-611, Nov. 2012.

[11] K. A. Shaw, "The Development of a Physics SelfEfficacy Instrument for Use in the Introductory Classroom," AIP Conf. Proc., vol. 720, no. 1, pp. 137140, 2004.

[12] M. A. Rahman, "Some Trends in the Praxis of Participatory Action Research," in The SAGE Handbook of Action Research, P. Reason and H. Bradbury, Eds. London: SAGE Publications Ltd, 2008, pp. 49-64.

[13] J. C. Blickenstaff, "Women and science careers: leaky pipeline or gender filter?," Gend. Educ., vol. 17, no. 4, pp. 369-386, 2005.

[14] S. Lauer, J. Momsen, E. Offerdahl, M. Kryjevskaia, W. Christensen, and L. Montplaisir, "Stereotyped: Investigating gender in introductory science courses," CBE Life Sci. Educ., vol. 12, no. 1, pp. 30-38, 2013.

[15] K. V. Tarnai-Lokhorst, "Where are the women? Perceived Barriers to Engineering Education: Exploring the feminist influences on curriculum in British Columbia and on the career choices of women with high school physics credit," in ASEE Conference, 2015, p. 26.1734.1-26.1734.15.

[16] "Undergraduate Programs and Admissions," The University of British Columbia, 2015. [Online]. Available: http://you.ubc.ca/admissions/canadianhighschools/bc-yukon/. [Accessed: 15-May-2015].

[17] "Canadian High School," Simon Fraser University, $2015 . \quad$ [Online]. Available: https://www.sfu.ca/students/admissionrequirements/cdn-highschool/bc_yukon.html. [Accessed: 15-May-2015].

[18] "Admission Requirements," 2015 University of Victoria, 2015. [Online]. Available: http://www.uvic.ca/futurestudents/undergraduate/admissions/thinking/admsrequirements.php. [Accessed: 15-May-2015].

[19] J. M. Swirsky and D. J. Angelone, "Equality, empowerment, and choice: what does feminism mean to contemporary women?," J. Gend. Stud., vol. 9236, no. April, pp. 37-41, 2015.

[20] M. H. Miner, W. O. Bockting, R. S. Romine, and S. Raman, "Conducting Internet Research With the Transgender Population: Reaching Broad Samples and Collecting Valid Data," Soc. Sci. Comput. Rev., vol. 30, pp. 202-211, 2012.

[21] K. V. Tarnai-Lokhorst, "From physics to where? Diagnosing the effect of a discovery-based teaching paradigm on continued barriers to women's entry to the physical engineering science professions ( RTP , Diversity )," Salt Lake City, 2018.

[22] A. J. Little and B. a. León de la Barra, "Attracting girls to science, engineering and technology: an Australian perspective," Eur. J. Eng. Educ., vol. 34, no. 5, pp. 439-445, Oct. 2009.

[23] “Acceleration Timer," Nasco, 2017. [Online]. Available: https://www.enasco.com/product/SB19009M.

[Accessed: 25-Sep-2017]. 


\section{APPENDIX A: CONCEPT FLOWCHART}
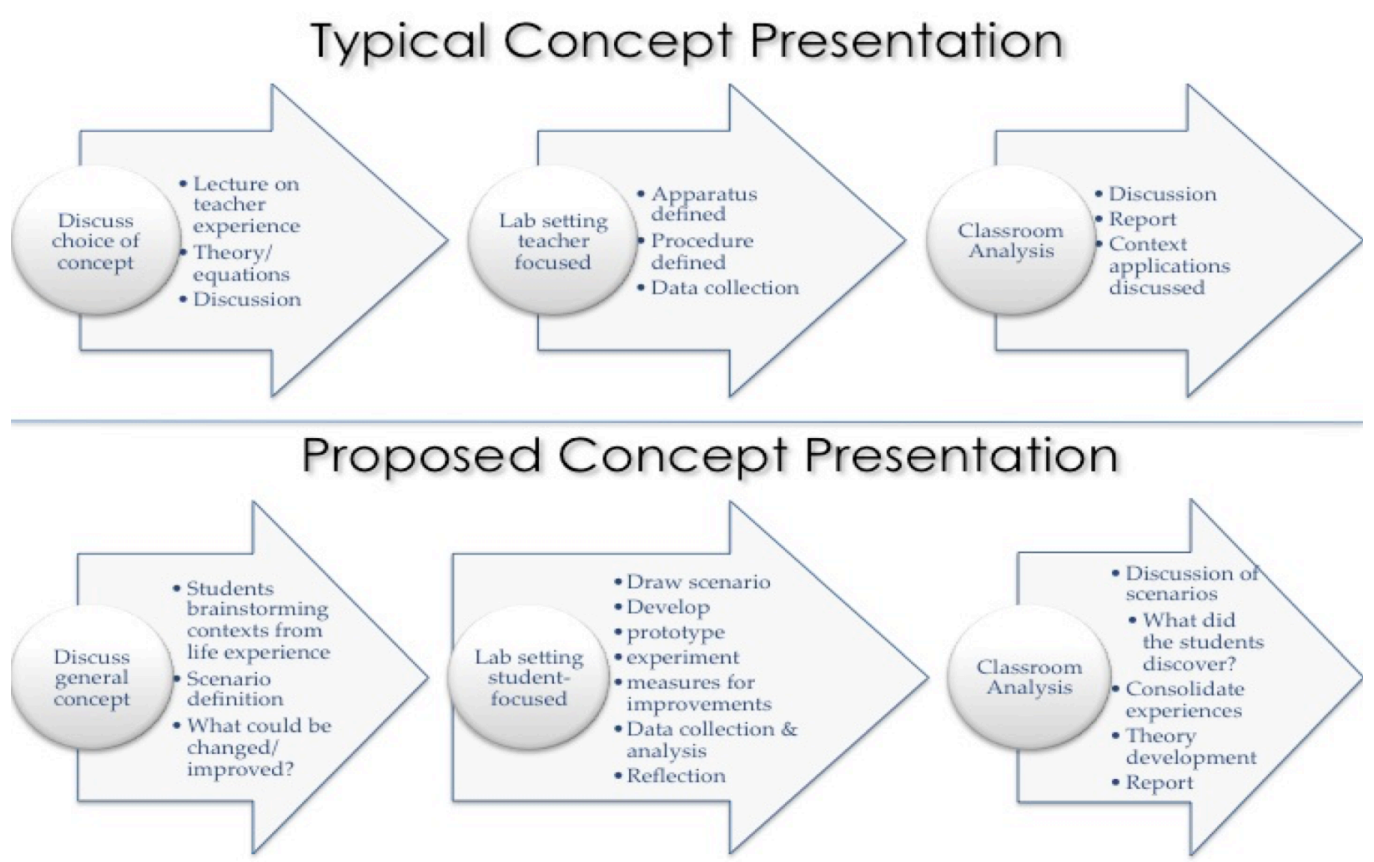

Figure 6: Typical verses new (proposed) teaching paradigm 